Anais da 3a Semana de Engenharia Civil da

Universidade Federal do Sul e Sudeste do Pará Jan 2020 - v. 2 - n.1

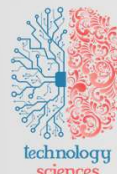

ISSN: 2674-6425

This article is also available online at: www.sapientiae.com.br

\title{
Análise das propriedades mecânicas de argamassa com adição de fibras vegetais amazônicas
}

A inovação aliada com sustentabilidade é a principal proposta da produção de concretos de baixa densidade com fibras vegetais. O presente trabalho utiliza fibras vegetais amazônicas - açaí e coco, e a adição de escória de alto forno, para a produção de concreto de baixo custo com propriedades aceitáveis. Concretos com a adição de $2 \%$ de fibras vegetais sem tratamento químico, com e sem adição de escória de alto forno, foram fabricados e avaliados mecanicamente e fisicamente, em diferentes idades de cura. Os agregados naturais foram caracterizados quanto a sua granulometria e microscopia de eletrônica de varredura (MEV). Em relação ao concreto obtido, avaliou-se a influência da escória na proteção dos agregados fibrosos na zona de interface matriz-agregado, tal como a manutenção de suas especificações estruturais. Para análise do comportamento mecânico, a etapa experimental envolveu ensaios de compressão axial, porosidade e ultrassom do concreto endurecido, que apresentaram resultados satisfatórios. Além das propriedades mecânicas, a avaliação das propriedades físicas, químicas e microestruturais demonstrou que a presença de plastificantes é necessária para reduzir a porosidade, otimizando propriedades específicas dos dois componentes - concreto e resíduos fibrosos. Os resultados obtidos atendem as normas vigentes, indicando a possibilidade de incorporação ao mercado do referido concreto.

\section{Analysis of mechanical properties of mortar with addition of Amazonian vegetable fibers}

Innovation combined with sustainability is the main proposition for the production of low density concrete with vegetable fibers. The present work uses Amazonian vegetable fibers - acai and coconut, and the addition of blast furnace slag to produce low cost concrete with acceptable properties. Concrete with the addition of $2 \%$ of untreated chemical fibers, with and without the addition of blast furnace slag, were fabricated and evaluated mechanically and physically at different curing ages. Natural aggregates were characterized by their particle size and scanning electron microscopy (SEM). Regarding the obtained concrete, the influence of slag on the protection of fibrous aggregates in the matrix-aggregate interface zone was evaluated, as well as the maintenance of its structural specifications. For analysis of mechanical behavior, the experimental stage involved axial compression, porosity and ultrasound tests of the hardened concrete, which presented satisfactory results. In addition to mechanical properties, the evaluation of physical, chemical and microstructural properties demonstrated that the presence of plasticizers is necessary to reduce porosity, optimizing specific properties of the two components - concrete and fibrous residues. The results obtained comply with current standards, indicating the possibility of incorporation to the market of said concrete.

Keywords: Low Density Concrete; Amazonian Vegetable Fibers; Sustainability; General Property.

Topic: Engenharia de Materiais

Reviewed anonymously in the process of blind peer
Received: 09/11/2019

Approved: 23/12/2019
Kyria Maria Alves da Silva

Universidade Federal do Sul e Sudeste do Pará, Brasil

http://lattes.cnpq.br/3608867271287304

kyriamary07@gmail.com

Lygia Maria Policarpio Ferreira (10)

Universidade Federal do Sul e Sudeste do Pará, Brasil

http://lattes.cnpq.br/9330364336746799

https://orcid.org/0000-0002-8956-3963

Ipolicarpio@unifesspa.edu.br
Referencing this:

SILVA, K. M. A.; FERREIRA, L. M. P.. Análise das propriedades mecânicas de argamassa com adição de fibras vegetais amazônicas. Technology Science, v.2, n.1, p.62-65, 2020. DOI: http://doi.org/10.6008/CBPC2674-6425.2020.001.0011 


\section{INTRODUÇÃO}

O concreto é um dos materiais de construção civil mais utilizados na Indústria da Construção do Civil - ICC, variando de pequenos à grandes empreendimentos. Savastano Junior (2000), ratifica que o emprego de novas matrizes na produção industrial ainda é muito pequeno devido a necessidade de adaptações no processo produtivo e pelo baixo conhecimento do mercado da área.

Ao avaliar o desenvolvimento de concreto com uma matriz cimentícia reforçada com fibras vegetais, deve-se considerar a absorção de energia pelo potencial de tenacidade das fibras, a interação matrizagregado e manutenção de características relacionadas a propriedades mecânicas de modo a viabilizar o uso do novo material inserido. É fato que, como afirma Callister Junior (2002), as propriedades dos compósitos são diretamente dependentes de: a) das propriedades individuais da fase matriz e da fase dispersa; b) da natureza da interface 'fase matriz - fase dispersa'; c) da geometria, isto é, configuração da fase dispersa.

As fibras vegetais amazônicas, neste traço utilizado, são baseadas nos resíduos produzidos na região. No caso das fibras de coco, a parte utilizada advém do uso do mesocarpo do fruto após a retirada d'água e parte comestível interna para consumo humano. Já as fibras de açaí utilizadas por sua vez, são retiradas do caroço do fruto após a retirada da polpa para o consumo do açaí. Em sua tese, Savastano Junior (2000), deixa claro a necessidade de proteger às fibras do ataque alcalino da matriz de cimento Portland comum. Os principais objetivos envolvidos estão relacionados à determinação da disposição adequada das fibras na matriz. É fato que aliado à esta finalidade, faz-se necessário testar às proporções de concreto e determinar o traço adequado.

\section{METODOLOGIA}

A partir da revisão científica realizada, determinou-se que de modo a proteger as fibras amazônicas inseridas e evitar tratamento químico destas se adicionou ao traço escória de alto forno - material pozolânico que diminui a alcalinidade da matriz. Para analisar a viabilidade da adição de fibras vegetais amazônicas no concreto, avaliou-se a evolução do aumento da resistência através do ensaio de compressão simples, ensaio de ultrassom do concreto e ensaio de absorção de água. Para avaliar o comportamento das fibras devido à sua morfologia, realizou-se ensaios de Microscopia Eletrônica de Varredura (MEV).

Os resíduos fibrosos selecionados para a composição da matriz foram definidos por granulometria, após redução mecânica da dimensão das fibras. Em ambas, a redução mecânica foi realizada por misturador em alta velocidade, nas fibras de coco tal mistura gerou a diminuição da dimensão em diferentes frações, já nas fibras de açaí a finalidade da mistura consistiu em desagregar a fibra do caroço.

Para padronizar o processo, utilizou-se a fração passante na peneira com abertura de \#4,5 mm e retidos na peneira com abertura de $\# 1,0 \mathrm{~mm}$, como demonstrado na Figura 1. Analisando as fibras de coco e as fibras de açaí, observou-se que estas possuem potenciais associados a fixação na matriz cimentícia gerando encaixe mecânico na matriz-agregado. 


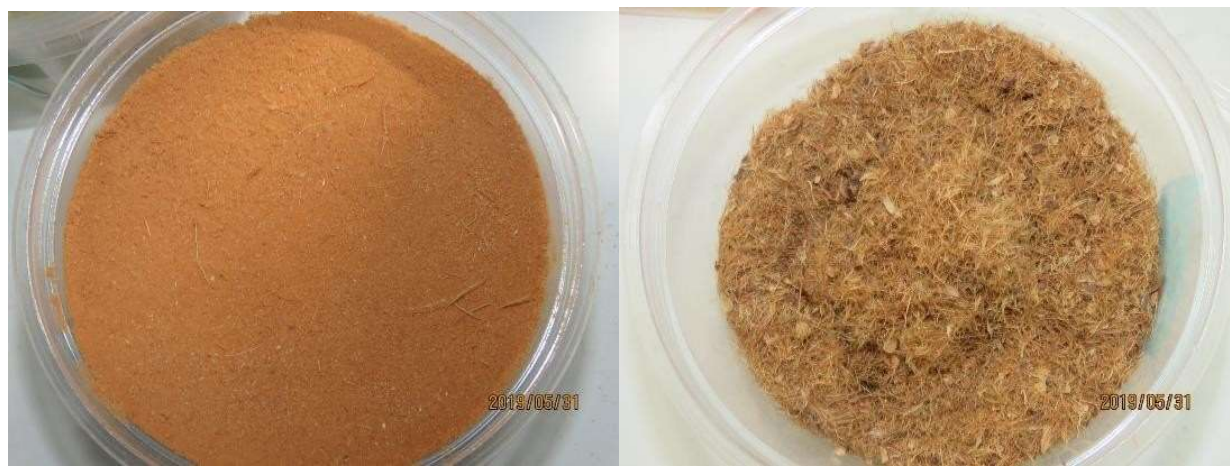

Figura 1: (a) - Fração da Fibra de Coco. (b) - Fração da Fibra de Açaí.

Compreende-se ao observar o detalhamento das Figura 2, que as fibras de açaí são mais alongadas e cilíndricas com feixes laterais. Por outro lado, as fibras de coco, possuem formato esférico, porém com protuberâncias superficiais. A partir da caracterização e da revisão realizada previamente, pode-se definir o traço do compósito, 1: 2.5: 2\%: 1\%: 0.45:0,001 (cimento: areia: fibras: escória: água/cimento: superplastificante).

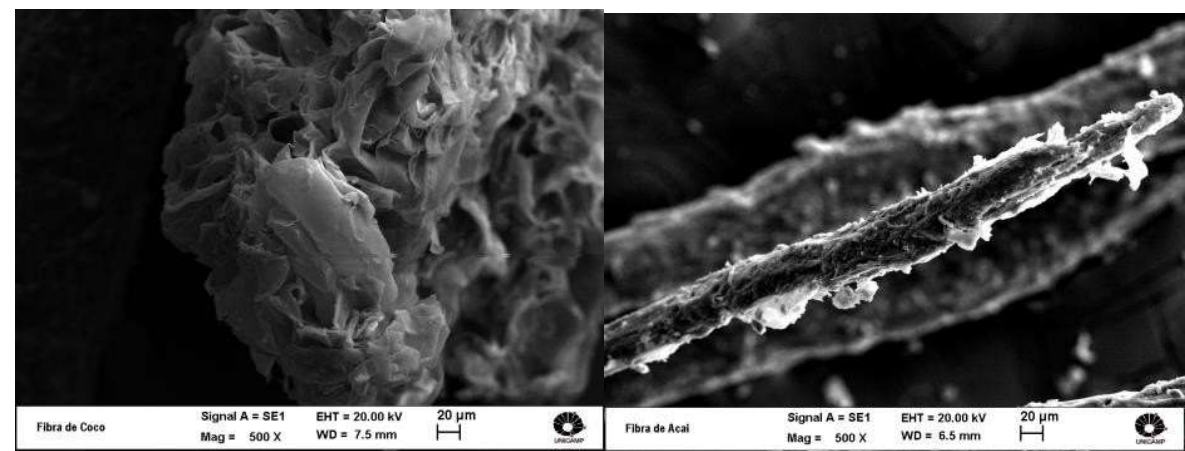

Figura 2: (a) - Mev da Fibra de Coco. (b) - Mev da Fibra de Açaí.

Ao realizar testes iniciais se observou a necessidade do plastificante para que os poros na matriz fossem reduzidos e conseguissem se agregar com melhor coesão. Na modelagem, necessitou-se de 10 minutos de homogeneização na argamassadeira. A primeira metade do tempo, foi necessária para as reações da matriz cimentícia e plastificante - inserindo nessa fase a areia cimento e água. Na segunda metade do tempo, a fibra foi inserida de modo que não se concentre em nenhuma região da massa. Após 24 horas, os corpos de provas foram imersos em solução alcalina para que pudessem ter o melhor processo de hidratação e evitar possíveis fissuras no processo.

\section{RESULTADOS E DISCUSSÃO}

Os ensaios de compressão axial e ultrassonografia do concreto foram realizados com o intuito de avaliar as propriedades mecânicas e qualidade da estrutura. Dessa forma, realizou-se a modelagem de corpos de prova analisados nas principais idades: aos 7 dias; 14 dias; 21 dias e 28 dias. A análise foi realizada de modo a acompanhar possíveis desintegrações da fibra devido à alta alcalinidade.

Os resultados do ensaio de compressão são apresentados na Tabela 1, onde é possível verificar que a escória foi altamente influente em todos os traços, seja com adição de fibra de coco ou com as fibras de 
açaí; ambas sofreram perda de propriedades mecânicas devido à alcalinidade do concreto quando desprotegidas.

O ensaio de ultrassom por sua vez, que avalia a qualidade do concreto utilizando como base a velocidade na qual um pulso de onda perpassa o meio; corrobora-se quanto mais veloz o pulso perpassa o meio, melhor relação matriz agregado existente. 0 ensaio de absorção de água, por sua vez, demonstrou que a escória auxiliou numa boa composição da matriz. O concreto fabricado com a adição de fibras de açaí, apresentaram melhores resultados quanto à qualidade, a alta tenacidade diminuiu o número de fissuras no interior da argamassa, porém a morfologia da fibra possibilitou uma maior absorção de água.

Tabela 1: Resultados dos Experimentos I, II e III.

\begin{tabular}{|l|l|l|l|}
\hline Traços & Resistência (MPa) & Qualidade & Porosidade \\
\hline Fibras de Coco (sem escória) & 14.99 & - & - \\
\hline Fibras de Coco (com escória) & 17.84 & Bom & $1,2 \%$ \\
\hline Fibras de Açaí (sem escória) & 14.38 & - & - \\
\hline Fibras de Açaí (com escória) & 18.74 & Bom & $2 \%$ \\
\hline
\end{tabular}

\section{CONCLUSÕES}

Infere-se a viabilidade da construção de compósitos com reaproveitamento de resíduos vegetais, visto que com as propriedades mecânicas obtidas este pode ser aplicado em revestimentos e acabamentos não estruturais. Avalia-se como perspectivas futuras a realização de testes variando o valor água-cimento para facilitar a utilização industrial de tais compósitos sustentáveis e utilização de outros valores de substituição de resíduos fibrosos.

\section{REFERÊNCIAS}

CALLISTER JUNIOR, W. D.. Ciência e engenharia de materiais: uma introdução. 5 ed. São Paulo: LTC, 2002.
SAVASTANO JUNIOR, H.. Materiais à base de cimento reforçado com fibra vegetal: reciclagem de resíduos para a construção de baixo custo. Tese (Doutorado) - Universidade de São Paulo, 2000. 